\title{
Garcilaso y el caso de la mala muerte del virrey Toledo*
}

\section{Garcilaso and the Case of the Evil Death of Viceroy Toledo}

\author{
CATHERINE JULIEN
}

Western Michigan University

Garcilaso Inca de la Vega concluye el segundo tomo de los Comentarios reales, publicado en 1617, con cinco capítulos que tratan acerca del gobierno de Francisco de Toledo. Este último, virrey del Perú entre 1569 y 1581, fue conocido principalmente por haber realizado la visita general del virreinato que sentó las bases institucionales de la administración espańola que duraría hasta fines de la época colonial. Felipe Guaman Poma de Ayala, autor de la misma época que Garcilaso, identificó algunos aspectos de la reforma toledana como responsables de muchos de los males que plagaban la sociedad andina de su tiempo, en particular la reducción de la población indígena a pueblos de tipo español y la introducción de corregidores. El autor de los Comentarios reales, en cambio, no se interesó en la visita: cuatro de los cinco capítulos que dedica a la época toledana se ocupan de la captura y ajusticiamiento de Topa Amaru en el Cuzco. ${ }^{1}$

* Catherine Julien (1950-2011) dejó este y otros textos en manos de Jeremy Mumford, quien recientemente le hizo llegar esta nota al director de Histórica para su publicación.

${ }^{1}$ Se trata de los capítulos XVI-XX de libro octavo de la Historia general. Uso «Inca» con mayúscula en referencia a Topa Amaru, e «inca» o «incas» para los miembros del grupo mayor.

HISTORIOด XLI.2 (2017): 169-188 / ISSN 0252-8894 
Topa Amaru era el hermano menor de Titu Cusi Yupanqui, el inca que gobernó la provincia autónoma de Vilcabamba entre 1559 y 1570. Fue con él que, en 1565, el licenciado Lope García de Castro - antecesor de Toledo y gobernador del Perú entre 1563 y 1569- negoció unas capitulaciones formales para que el inca aceptase ser vasallo del rey de España e incorporase la provincia de Vilcabamba al Perú de los españoles. ${ }^{2}$ Castro también concedió a Titu Cusi una serie de mercedes para que salga de Vilcabamba. ${ }^{3}$ En ese sentido, aunque las relaciones entre Vilcabamba y el Perú han sido difíciles de desentrañar, podemos aseverar que Toledo prefería abrogar el acuerdo negociado por Castro y confirmado por Felipe II para acabar de una vez con ese vestigio del poder incaico. ${ }^{4}$

Cuando se supo de la muerte de Titu Cusi, el ejército enviado a Vilcabamba para capturarlo tomó preso a su hermano Topa Amaru. Este fue llevado al Cuzco e hizo su entrada el 21 de septiembre de 1572. Después de un proceso criminal y la catequización para que pudiera recibir el bautizo antes de morir, Topa Amaru fue degollado en la plaza de esa misma ciudad el 24 de septiembre de aquel año. En los cuatro capítulos que dedica a este tema en sus Comentarios reales, Garcilaso apenas menciona la campańa militar, pues prefiere contar los eventos que rodearon la muerte del inca.

Junto con esta historia, Garcilaso narra el castigo efectuado por Toledo para con los mestizos «hijos de los conquistadores» del Cuzco por haberse «conjurado con el príncipe Tupac Amaro, y con los demás incas para alzarse con el reino». Menciona el destierro de varios mestizos, incluso a Juan Arias Maldonado, hijo de Diego Maldonado. ${ }^{5}$ Algunos de los incas del Cuzco fueron enjuiciados, por haberse carteado con su pariente en Vilcabamba para convencerlo de que no dejara esa región, ${ }^{6}$ pero es importante señalar que no hubo ningún motín de mestizos durante ese tiempo.

2 Guillén Guillén 1977.

3 Nowack 2006.

4 Julien 2007.

5 Garcilaso 1960: 167.

6 Nowack y Julien 1993. 
Entre los siete acusados en el juicio figuraban algunos de los incas más importantes del Cuzco: don Carlos Inca, el hijo de Paullu Topa; don Diego Cayo, descendiente de Pachacuti que había gobernado Tawantinsuyu en algún momento como teniente de Huayna Capac; y don Alonso Tito Atauchi, hijo de otro inca del mismo nombre, quien tenía a su cargo la propiedad que pertenecía a la panaca de Huayna Capac. Fueron sentenciados al destierro y, después del ajusticiamiento de Topa Amaru y dos de sus capitanes, ellos y algunos de los presos tomados en Vilcabamba salieron caminando a Lima, rumbo al destierro en España. ${ }^{7}$ El motín de mestizos mencionado por Garcilaso tendría que ser aquel que tuvo lugar en 1567, cuando Juan Arias Maldonado fue culpado de participar junto con otros mestizos y algunos cuantos espańoles. ${ }^{8}$ Sin embargo, en 1572 Maldonado estaba en España, siguiendo un pleito con el fiscal. Garcilaso tuvo que haber conocido mejor los detalles del motín, porque el propio Maldonado lo visitó en Montilla dos veces en aquellos años. ${ }^{9}$

A lo mejor Garcilaso estaba equivocado o mal de la memoria. Cuando leemos lo que escribió sobre la época toledana en contraposición de la documentación más contemporánea a los eventos, encontramos muchos errores de este tipo, ya que confunde personas, fechas y eventos. Para ser justos, debemos notar que, en este aspecto, Garcilaso se asemeja a otros autores que escribieron sobre la época de la conquista sin consultar documentación alguna de archivo. ${ }^{10}$ En su época, solamente Antonio de Herrera y Tordesillas (1601-1615) tuvo el acceso necesario para poder representar aquella época de una manera fehaciente. Garcilaso, más bien, tenía que apoyarse en su propia memoria de aquellos tiempos o en la vox populi.

7 Parece que ninguno fue embarcado (Nowack y Julien 1993).

8 López Martínez 1967.

9 Garcilaso 1960: 168. Tampoco se explica que no se mencione a Titu Cusi. Juan Arias Maldonado debió haber estado bien informado de las negociaciones de don Titu Cusi cuando llegó a Espańa, por lo que sorprende que no haya hablado sobre el tema con Garcilaso.

${ }^{10}$ Ocampo (1906) y Alcaya (1906) también cometen muchos errores cuando escriben de la época pretoledana. 
Si leemos a Garcilaso con los criterios del historiador, su texto presenta serios defectos. Pero sería error nuestro tacharle de mentiroso sin pensar en las posibles fuentes de lo que cuenta. Hay otras formas de representación que están obrando en el fondo de lo que Garcilaso narra sobre la época toledana. Por ejemplo, no era necesario terminar la historia de la actuación del virrey Toledo en los Andes con su muerte en España. Garcilaso lo incluye «porque no vaya sola y desacompañada la muerte del Inca don Felipe Tupac Amaro»; por eso, «será razón [que] demos cuenta brevemente de la que tuvo el visorrey don Francisco de Toledo». ${ }^{11}$ A continuación, narra el fin trágico que tuvo el virrey luego de su retorno a España. Su muerte se equipara a la muerte del Inca. El mismo contraste nos hace entender la muerte de Topa Amaru como una muerte ejemplar. Garcilaso elije ejemplos de la buena y la mala muerte para cerrar su obra maestra. Y, de hecho, él no es el único autor andino que representa la muerte de Toledo de esta manera; luego de examinar el texto de Garcilaso a la luz de los documentos, volveremos a este tema.

\section{LA BUENA Y LA MALA MUERTE}

A principios del siglo XVII, cuando Garcilaso escribió los Comentarios reales, ya estaba bien desarrollada la literatura de ars moriendi. Su importancia aumentó durante el curso del siglo XVI, lo que reflejaba la preocupación creciente sobre el pasaje de la vida a la muerte. Ningún cristiano podía prever las circunstancias de su partida y «las agonías de la muerte» eran momentos críticos para la salvación. Lo deseable era prepararse bien: se debía, primero, encargar el alma y los bienes mediante un testamento escrito y, luego, recibir los sacramentos y la extremaunción. Era deseable también estar consciente hasta el momento mismo de la muerte, para no dejar el alma expuesta a las maquinaciones de Satanás, que estaba especialmente activo en los últimos momentos de la vida. Lo indeseable era morir de manera repentina, sin prepararse para la salvación. Parte de la conceptualización de la «buena muerte» era hacerlo en la cama, con todas las disposiciones y preparativos hechos, 
y rodeado por familiares. En cambio, la muerte súbita en la calle era la imagen típica de la «mala muerte». ${ }^{12}$

Topa Amaru murió en el cadalso y, por eso, no parecía ser candidato para una «buena muerte». Justamente por la escenificación pública del acto, el ajusticiamiento se podría poner en práctica como una muerte ejemplar, sobre todo «si el condenado se arrepentía en el último instante y sabía morir digna y cristianamente». Así, "podía constituirse en un eficaz ejemplo demostrativo de que todos, incluso el más miserable, podía realizar la muerte del buen ladrón y salvarse». ${ }^{13}$

El Topa Amaru de Garcilaso era un inocente, no solamente por su forma de comportarse en el momento de la muerte, sino por todo lo que hizo en los días anteriores. Es más, para Garcilaso, el Inca no había cometido ningún delito que justifique su condena: era inocente desde el punto de vista de la ley. Los asaltos y robos de los Incas de Vilcabamba fueron cometidos en época de Manco Inca, su padre. Según Garcilaso, el Inca fue acusado de haber conjurado con sus parientes para levantarse y matar a los españoles, pero esto era imposible, como él bien sabía, "pues su padre no había podido con doscientos mil hombres de guerra sujetar a doscientos españoles que tuvo cercados en aquella misma ciudad [Cuzco], que no era de imaginar que él pretendiese rebelar contra ellos». En vez de resistir a las tropas del virrey que entraron a Vilcabamba para capturarle, «vino con ellos de buena gana», pues esperaba que «le iban a hacer alguna merced como se la hicieron a su hermano don Diego Sairi Tupac». ${ }^{14}$ Pero Garcilaso se equivocaba: los incas ofrecieron resistencia a las tropas que Toledo mandó para capturar al Inca.

El autor pinta a Topa Amaru como un buen cristiano en todo momento, con una conducta ejemplar en los días antes de su muerte, cuando fue sujeto a una catequización intensa:

Demás del buen ánimo con que recibió la muerte aquel pobre príncipe [...] dejó lastimado los religiosos que le ayudaron llevar su tormento [...] y se

\footnotetext{
${ }^{12}$ Martínez Gil 1993: 140-149.

13 Ib.: 155 .

${ }^{14}$ Garcilaso 1960: 169.
} 
consolaron con la magnanimidad que en aquel paso mostró y tuvieron que contar de su paciencia y actos que hacía de buen cristiano, adorando las imágenes de Cristo Nuestro Señor y de la Virgen su madre que los sacerdotes le llevaban delante. ${ }^{15}$

Topa Amaru dijo, luego de ser sentenciado, que recibiría la muerte "contento y consolado». ${ }^{16} \mathrm{La}$ tranquilidad fue característica de su comportamiento hasta el momento mismo de su ejecución. Ese día, Topa Amaru fue llevado por las calles en una mula hasta la plaza, donde se había erigido un tablado. Le esperaban 300.000 personas. A su llegada, una banda de mujeres soltó un gran alarido que expresaba el deseo de ser muertas para acompańarle. El ruido de los gritos y el vocerío era tal que los sacerdotes que acompañaron al Inca incluso le pidieron «que mandase callar a los indios». Garcilaso describe lo que pasó:

El Inca alzó el brazo derecho con la mano abierta y la puso en derecho del oído y de allí la bajó poco a poco hasta ponerla sobre el muslo derecho. Con lo cual sintiendo los indios que les mandaba callar, cesaron de su grita y vocería y quedaron con tanto silencio que parecía no haber ánima nacida en toda aquella ciudad. ${ }^{17}$

Los españoles y el virrey, que estaba mirando oculto desde de una ventana, quedaron asombrados por la obediencia mostrada por la multitud como respuesta a ese gesto. Cuando le cortaron la cabeza, «recibió aquella pena y tormento con la grandeza que los Incas y todos los indios nobles suelen recibir cualquiera inhumanidad y crueldad que les hagan». ${ }^{18}$ Aún sin esta temprana referencia al famoso estoicismo del indio, la muerte del Inca — tal como fue representada por Garcilaso- cumple con las pautas propias para ser considerada como un ejemplo de la buena muerte.

Por el contrario, Toledo sufrió una mala muerte. Garcilaso no revela al principio de los cinco capítulos que dedica a su gobierno que el virrey fuera a terminar mal, pues señala que fue elegido "por su mucha

\footnotetext{
${ }^{15}$ Ib.: 171 .

16 Ib.: 169 .

${ }^{17}$ Ib.: 171 .

${ }^{18} \mathrm{Ib}$.
} 
virtud y cristiandad» y nota que «recibía el Santísimo Sacramento cada ocho días». ${ }^{19}$ El virrey queda relegado en la narración cuando Garcilaso presenta el mal tratamiento recibido por los incas y mestizos del Cuzco luego de ser capturado Topa Amaru. Toledo solamente viene a ser protagonista en el quinto y último capítulo, cuando regresa a España en vísperas de su muerte. Garcilaso afirma que murió trágicamente, no tanto por razón de su poca piedad como en el caso de Topa Amaro, sino por sus pecados de avaricia y orgullo:

Cumplido el término de su visorreinado, que fue muy largo, que según dicen pasó de los dieciseis años, se vino a España con mucha prosperidad y riqueza, que fue pública voz y fama que trajo más de quinientos mil pesos en oro y plata. Con esta riqueza y la buena fama de ella, entró en la corte, donde pensó ser uno de los grandes ministros de España por los muchos servicios que imaginaba haber hecho a la majestad católica en haber extirpado y apagado la real sucesión de los Incas reyes del Perú. ${ }^{20}$

Toledo gobernó al Perú algo más de doce años y no trajo semejante cantidad de dinero a Espańa, pero lo más interesante para nosotros es su recepción por el rey: «La católica majestad [...] recibió el virrey no con el aplauso que él esperaba, sino muy en contra. Y en breves palabras le dijo que se fuese a su casa, que Su Magestad no le había enviado al Perú para que matase reyes, sino que sirviese a reyes». ${ }^{21}$ Este es el famoso refrán que tan fácilmente se ha mantenido en la memoria. Según Garcilaso, Toledo cayó en dos «desfavores»: el uno, por haber sentenciado a Tupa Amaru a la muerte; y el otro, por haber excedido en sus cobranzas a la Hacienda Real. Citando como fuente «los émulos que avisaron al consejo real», Garcilaso escribe lo siguiente:

Sus criados y ministros [de Toledo] habían cobrado su salario pesos por ducados, que como eran cu[ar]enta mil ducados tomaban cada año cuarenta mil pesos y que por el largo tiempo que el visorrey había asistido en el

\footnotetext{
${ }^{19}$ Ib.: 164 .

${ }^{20}$ Ib.: 172 .

${ }^{21} \mathrm{Ib}$.
} 
gobierno de aquel imperio pasaban de ciento y veinte mil ducados los que se habían hecho de daño y agravio a la hacienda real. ${ }^{22}$

La cuantía de cuarenta mil ducados es relevante, y volveré a mencionarlos más adelante, pero quiero seguir aquí con lo que escribió Garcilaso. Dice que se hizo el embargo de «todo el oro y plata» que llevó consigo el virrey, luego del cual «Don Francisco de Toledo, viendo el segundo disfavor que igualaba con el primero, cayó en tanta tristeza y melancolía que murió en pocos días». ${ }^{23}$

Garcilaso no precisa las circunstancias de la muerte del virrey, pero deja entendido que la melancolía y la tristeza ocasionadas por el rechazo de su soberano fueron los motivos más importantes. Como el propósito de un caballero como Toledo en todo momento de su vida era servir a su rey, lo peor que le podría haber pasado era morir en desgracia. Aun cuando Guamán Poma presenta la imagen de Toledo cayéndose muerto en una silla, Garcilaso la describe como una tragedia.

\section{EL RETORNO DEL VIRREY}

Es verdad que Toledo murió pocos días después de volver a su tierra, tal como lo cuenta Garcilaso, pero en circunstancias diferentes. La documentación que se conserva acerca de lo que pasó después de la llegada de Toledo a España nos proporciona una imagen distinta de las cosas. $\mathrm{Al}$ mismo tiempo, nos sirve para rectificar por completo lo que cuenta Garcilaso. Abordaremos brevemente los puntos relevantes.

Garcilaso cuenta que Felipe II reprendió a Toledo cuando le fue a besar la mano en la corte y que pronunció su famoso refrán en aquella ocasión. Este rechazo puso tan triste a Toledo que murió pocos días después. Pero es poco probable que el rey haya reprendido al virrey de esta manera, si es que Toledo logró verse con el rey. Toledo estaba gravemente enfermo cuando llegó a España. Tal estado se remonta a 1574, cuando participó en la guerra contra los indios chiriguanos en el oriente del actual territorio

${ }^{22} \mathrm{Ib}$.

${ }^{23} \mathrm{Ib}$. 
boliviano. Nunca recuperó su salud y pidió licencia para dejar su cargo y volver a España numerosas veces en los siguientes años. El rey la aceptó finalmente en 1580 y nombró a Martín Enríquez como su sucesor. Llegado Enríquez al puerto de Paita, Toledo se embarcó para España y arribó a Sevilla el 15 de septiembre de 1581. En aquel momento, Felipe II estaba en Lisboa, asegurando la corona de Portugal para Espańa. Entonces Toledo pasó directamente allí para besarle la mano. Toledo escribió en una carta del 28 de enero de 1582, dirigida a Mateo Vázquez, secretario de Felipe II, que no había podido «besar las manos de su majestad con la verdad que Dios sabe que deseaba, y a echarme a mí y a mis méritos y trabaxos a sus pies» porque su salud se lo impedía. Pidió irse a su casa porque la humedad de Lisboa, «que es contraria a mi disposición de que yo tengo esperiencia», le hacía mal, tal como le habían aconsejado los médicos del rey. ${ }^{24}$ Es posible que Toledo lograra verse brevemente con Felipe II porque el capitán Francisco de Barrasa, mayordomo de Toledo y su acompañante en el viaje de retorno, escribió que este llegó a su tierra "tan viejo y enfermo como vuestra magestad le vio». ${ }^{25}$ Toledo murió en Escalona, en el condado de Oropesa, el 21 de abril de 1582. ${ }^{26}$ Aun cuando tuviera un encuentro con el rey, es dudoso que hubiera podido hacer la deseada relación de sus servicios e igualmente dudoso que Felipe II le reprendiera como escribió Garcilaso. ${ }^{27}$

${ }^{24}$ Levillier 1935-1942, I: 197-198. Toledo parece desalentado en la carta. No era la última carta del virrey, como Levillier pensaba (1956: 16). Hubo otra, con fecha del 8 de febrero de 1582, también dirigida a Vázquez (Fernández Navarrete, Salvá y Sáinz de Baranda 1842-1895, XCIV: 545-547). Parece que no había salido aún de Lisboa. La segunda carta revela que Toledo ya sabía del problema sobre su cobro de una ayuda de costa en Lima (que menciono más abajo). También se percata de que Vázquez estaba alineado con el Consejo de Indias en su contra. No hay evidencia de que se había visto con el rey.

${ }^{25}$ Levillier 1921-1926, VII: 469; y 1956: 16.

${ }^{26}$ Julien 1999.

${ }^{27}$ Ernst Shäfer (1931) y Roberto Levillier (1956) escribieron cada uno ensayos sobre las relaciones entre Toledo y las Audiencias de Lima y Charcas, por un lado, y entre Toledo y Felipe II, por otro. Sacan conclusiones opuestas: Shäfer se enfoca en el apoyo que Felipe II le prestaba a Toledo y en el poder que tenía el virrey para gobernar, en contra de lo que hubiera querido el Consejo; Levillier, en cambio, argumenta que Toledo 
El rechazo puede tomar distintas formas e, incluso si Felipe II no hizo tal cosa en vida, podríamos interpretar lo que pasó luego de su muerte como un tipo de rechazo. Es verdad, como dice Garcilaso, que Toledo esperaba recibir una merced en gratificación por sus largos años de servicio como virrey del Perú. ${ }^{28}$ Aun antes de dejar el Perú, pidió la encomienda de Andahuaylas en el Cuzco, vacante desde 1570 por la muerte de Diego Maldonado. ${ }^{29}$ También solicitó el cargo de clavero en la Orden de Alcántara, de la cual ya era comendador. Parece que Felipe II le concedió el cargo en su orden —aunque no hubo tiempo para gozarlo—,${ }^{30}$ pero nunca llegó a conferirle ninguna encomienda o renta. Para un caballero que vivía para servir al rey, esta falta de reconocimiento constituía un fuerte rechazo.

Este no es el lugar para tratar en detalle lo que le sucedió a Toledo, pero es importante tener alguna idea acerca de por qué Felipe II no llegó a concederle la merced que deseaba. En suma, lo que imposibilitó la concesión de la merced fueron los juicios que tuvieron lugar en el Consejo de Indias cuando Toledo regresó a España. Primero, el Consejo de Indias descubrió que cuánto había cobrado de sueldo el virrey antes de volver a España. Su sueldo, durante los doce años que ocupó el cargo de virrey, era de 40.000 ducados anuales. Sin embargo, por haber recibido el pago en barras en vez de en reales, libró la cantidad de 41.000 ducados en vísperas

fue abandonado por el rey. Es importante mencionar que Levillier no citó el trabajo de Shäfer ni utilizó la serie de consultas entre el Consejo y el rey que fueron minados por este en su estudio. Ni el uno ni el otro se preocupó de lo que pasó luego de la muerte del virrey. Según Shäfer, «la célebre anécdota de cómo Felipe II le reprendiese por esta muerte a D. Francisco de Toledo cuando, después de vuelto, se presentó al rey, tiene que ser del todo apócrifa, porque un gesto tan teatral es absolutamente extraño al carácter de D. Felipe» (1931: 107, nota 18). Levillier lo tacha de «una fabula garcilasista» (1956: 15). ${ }^{28}$ Un memorial del conde de Oropesa menciona a las mercedes recibidas por otros virreyes y gobernadores del Perú. Según este documento, el virrey Antonio de Mendoza había recibido 20.000 ducados de renta que todavía gozaban sus herederos; el licenciado Lope García de Castro obtuvo una renta de 6000 ducados anuales en la Casa de la Contratación; y los hijos de Martín Enríquez tenían la encomienda de Piedrahita en España, además de una pensión de 4000 ducados en el Perú por dos vidas (Levillier 1921-1926, VII: 477).

${ }^{29}$ Archivo General de Indias, Lima 1, N. 137.

${ }^{30}$ Levillier 1956: 16; y 1921-1926, VII: 469-470. 
de su retorno a España, lo cual hizo con la aprobación de los oficiales reales en Lima. ${ }^{31}$ Garcilaso anotó que Toledo había calculado su sueldo en "pesos por ducados», por lo que había cobrado 120.000 ducados de más. Así, aunque el cronista parece tener alguna memoria del asunto, está errado tanto en las cantidades como en la naturaleza del problema.

Garcilaso no tiene presente el otro pleito que tuvo origen cuando Toledo regresó a la Península. El Consejo de Indias descubrió que había cobrado una ayuda de costa de 10.000 ducados por cada año de los cinco en que estuvo ocupado en la visita general, es decir 50.000 ducados en total. En una carta de 1572, Felipe II había autorizado el pago de los salarios para la visita «de condenaciones de culpados [...] y que los indios ayudasen con comidas y lo que faltase se supliese del crecimiento de tributos». La Audiencia de Lima aprobó una ayuda de costa de 10.000 ducados cada año, pero Toledo quería que le pagasen otro sueldo, como se hacía con los oidores que salían a visitar. Antes de volver a España, el 21 de abril de 1581, el virrey, con los autos y pareceres de los oficiales, mandó librar un pago de 50.000 ducados del receptor general de la visita, quien tenía a cargo una cuenta donde ingresaba el dinero de la tasa que se separaba para pagar «justicias». El Consejo de Indias le había advertido que ellos decidirían lo que era justo. Por eso, al descubrir que Toledo había ordenado el pago, el fiscal lo enjuició por los 50.000 ducados y los intereses respectivos.

Los testamentarios del virrey, representados por su sobrino, el conde de Oropesa, elaboraron su propia relación de demandas, incluyendo el sueldo correspondiente al tiempo de su viaje de regreso, un ídolo y unos lienzos llevados por el juez que embargó los bienes del virrey, y los gastos del virrey relacionados con la visita, calculados en 69.000 ducados. En el curso del proceso, murieron dos de los jueces y hubo un intento de llegar a un concierto entre las partes que fracasó; pero la causa no se terminó

${ }^{31}$ Para un mejor resumen de los cálculos que se hizo para llegar a los 41.000 ducados y cómo fueron recibidos en Sevilla, véase Levillier 1921-1926, VII: 502-504. Si dividimos los 41.000 ducados por los doce años en que el virrey recibió un sueldo en el Perú, sacamos una cifra de 3416 ducados por año, que sería el promedio de las fluctuaciones entre la moneda en barras y la moneda en pesos ensayados. 
hasta 1598, cuando fue sentenciada definitivamente. Los testamentarios recibieron cinco meses de sueldo y no se reconoció el pago de los intereses de los 50.000 pesos. Como los pleitos concluyeron en agosto de 1598, en vísperas de la muerte de Felipe II, el 13 de septiembre del mismo año, ${ }^{32}$ no hubo tiempo para que el rey concediera la merced al antiguo virrey. Parece que se concluyó el asunto con el deceso del monarca. A fin de cuentas, lo que venció a Toledo fue la muerte.

Todo lo anterior se podría pintar como una tragedia, pero aún cuando el caso de la mala muerte pintado por Garcilaso no deja de tener un aire de veracidad, algo falta. Garcilaso mencionó otro «desfavor» en que recayó el virrey cuando llegó a España: el rechazo del rey por haber ajusticiado a Topa Amaru. Aunque la documentación que tenemos se relaciona exclusivamente con los pleitos, hay algunas referencias escasas a la actuación de Toledo al hacer la guerra contra los incas de Vilcabamba y al ajusticiamiento del Inca. Aparecen en los memoriales presentados por sus testamentarios y siempre se presentan en el contexto de una lista de los servicios que hizo su pariente en el Perú que merecían gratificar. ${ }^{33}$ No veían la actuación de su pariente respecto a los incas de Vilcabamba como un lastre, por lo que podemos inferir que las autoridades españolas ante las cuales presentaron sus memoriales vieron la actuación de Toledo con los mismos ojos.

\section{LA MUERTE DEL INCA EN LA MEMORIA ANDINA}

Garcilaso estaba y vivía en España cuando Toledo llegó y durante todo el tiempo que duraron los pleitos. Bien podríamos pensar que lo que

\footnotetext{
${ }^{32}$ Se conservan tres sentencias. Primero, en sentencia definitiva se les concedió a los testamentarios los cinco meses de sueldo que el virrey no había cobrado. El 10 de agosto de 1598, este asunto fue visto en grado de revista con fallo a favor de la sentencia definitiva, con notificación del fiscal del 7 de septiembre del mismo ańo. Finalmente, el 11 de agosto de 1598, los testamentarios fueron absueltos de pagar los intereses de los 50.000 ducados y se puso perpetuo silencio sobre el asunto. Fue decidido el 11 de agosto de 1598, con notificación del fiscal del 7 de septiembre de 1598 (Levillier 1921-1926, VII: 524-529).

${ }^{33}$ Levillier 1921-1926, VII: 493-494 y 501. La única excepción parece ser una referencia a «la justicia que hizo de los ingas» en una consulta del Consejo de Indias (Shäfer 1931: 105), pero es probable que se refiera al juicio que sostuvo contra los incas del Cuzco.
} 
escribió reflejaba algo de lo que pasó allí o, por lo menos, lo que se contaba en la calle acerca del virrey. Pero otra posibilidad se sugiere. Existe otro autor que representa la muerte del virrey como contrapunto a la muerte del Inca y de una manera que nos hace recordar a Garcilaso: Felipe Guaman Poma de Ayala. La semejanza entre estos dos autores adquiere importancia porque no hay motivos para pensar que un autor había conocido lo que escribió el otro; no podría ser un caso de préstamo textual sino de una transmisión oral.

Como Garcilaso, Guaman Poma sitúa la muerte de Topa Amaru en primer plano cuando escribe sobre la época toledana, aunque da cierta importancia también a la visita general y la reforma llevada a cabo por el virrey, lo que está ausente por completo en los capítulos de Garcilaso. Ambos autores se refieren a Topa Amaru en términos que destacan su estatus real: mientras que Garcilaso le llama «el príncipe», Guaman Poma usa el título "ynfante». A este último no le interesa el tema de los mestizos, pero sí menciona el juicio contra los incas del Cuzco que ocurrió al mismo tiempo que la campaña en Vilcabamba ${ }^{34}$ y se refiere a Carlos Inca y Alonso Tito Atauchi por sus nombres.

Ciertos temas relacionados con Topa Amaru son de interés especial para ambos autores, sobre todo su captura y los eventos relacionados con su muerte. Ni Guaman Poma ni Garcilaso se interesan en la campaña de Vilcabamba, que es quizás la mayor diferencia entre sus relaciones y lo que otros autores que escribieron en los años inmediatos a los eventos. ${ }^{35}$ Con referencia a la captura de Topa Amaru, ambos autores insisten en que el Inca no ofreció resistencia a los españoles. Guaman Poma utiliza la captura de Topa Amaru para subrayar uno de los puntos centrales de su obra: los andinos no habían resistido a los españoles, ni tampoco se habían rebelado como Gonzalo Pizarro y Francisco Hernández Girón. ${ }^{36}$

${ }^{34}$ Guaman Poma 1992, II: 417.

${ }^{35}$ Como, por ejemplo, una relación atribuida a Tristán Sánchez que trata del gobierno del virrey Toledo, que parece ser de 1572 (Pacheco, Cárdenas y Torres de Mendoza 1864-1884, VII: 263-279). La muerte de Topa Amaru ocupa un capítulo (Ib.: 279-282). 36 Guaman Poma 1992: 414. 
Garcilaso también niega que los incas de Vilcabamba hayan combatido a las tropas de Toledo, pero no niega la conquista.

Ambos autores narran algunos detalles relacionados con la llegada de Topa Amaru al Cuzco. Según Guaman Poma, el Inca entró descalzo al Cuzco con una cadena de oro al cuello, llevado por el capitán Martín García de Loyola, mientras que el virrey observó la procesión desde la casa de su posada. Delante de él, otro capitán cargaba un ídolo capturado en Vilcabamba, identificado por el autor como Huanacauri, pero que podemos identificar como Punchao. ${ }^{37}$

Guaman Poma omite referencias a la catequización de Topa Amaru, pero nota que fue bautizado antes de ser degollado. A diferencia de Garcilaso, que pinta la escena con más detalle, a este autor no le interesa tanto el drama que tuvo lugar en el día de la muerte: no menciona el alarido que ocurrió cuando el Inca llegó a la plaza del Cuzco ni cómo el Inca calló el ruido con un señal de la mano - aunque sí describe el llanto general que estalló después de que le fuera cortada la cabeza-. Para el cronista, el tema de más interés fue la falta de jurisdicción que tenía el virrey para juzgar al Inca.

En su narración, el obispo Sebastián de Lartaún pidió por la vida del Inca y, luego, «unas mugeres prencipales del Cuzco». Pero era inútil cualquier suplicación porque Toledo se había enojado cuando fue informado que «abia dicho el Ynga, como muchacho y con rrazón, cuando le enbió a llamar, dixo que no quería yr a un mayordomo de un señor Ynga como él». ${ }^{38}$ Desde el punto de vista de Guaman Poma, Toledo no tenía jurisdicción para convocar al Inca, ni mucho menos para juzgarlo y sentenciarlo a muerte. Por ello, el autor reprende al virrey:

Mira, cristiano, esta soberbia y demás de la ley de pérdida que hizo en servicio de Dios y de su Magestad Francisco de Toledo. ¿Cómo puede sentenciar a muerte al rey ni al príncipe ni al duque ni al conde ni al marqués ni al cauallero un criado suyo, pobre cauallero desto? Se llama alsarse y querer ser más que el rrey. Destos dichos caualleros sólo con su poder tiene de conoser

\footnotetext{
${ }^{37}$ Julien 2002.

${ }^{38}$ Guaman Poma 1992, II: 417.
} 
su causa y sentencia el rrey con su persona propia, ni puede conoser la dicha causa su bizorrey ni su audiencia rreal, cino entregalle a sus manos para que como señor o poderoso le perdone o le sentencie a su bazallo mayor de todo uneuerso mundo. Esto es la ley. ${ }^{39}$

Pero ¡la ley de quiénes? Aunque la divinidad de los reyes europeos complicaba la cuestión de si se podría matar a un rey en aquellos tiempos, no estaba en juego la cuestión de quién podría matarle. No es fácil probar que esta idea tiene orígenes en un algún fuero andino, pero hay algunas evidencias a su favor. ${ }^{40}$ En el caso de Topa Amaru, no hay por qué pensar que los españoles le dotaban el estatus de rey. Estaba vigente una capitulación con Titu Cusi, el hermano mayor de Topa Amaru, que exigía que el Inca aceptase ser vasallo del rey de España. Titu Cusi juró su vasallaje en 1567 y la capitulación estaba aprobada por Felipe II. Podríamos acusar a Toledo de ser duro al imponer la pena capital en este caso, pero no hubo ningún impedimento legal.

En la crónica de Guaman Poma, la muerte del virrey no sigue inmediatamente después de la muerte del Inca, sino luego de unos capítulos sobre una visita en la época de Topa Inca en que participó un pariente del autor. ${ }^{41}$ Cuando es tema, merece una página entera, acompañada por el dibujo del virrey asentado en una silla. Guaman Poma escribe que Toledo regresó a España, pero no recibió licencia para entrar a la cámara del rey para besarle la mano: "con este pesadumbre se fue a su casa y no comió y se asentó en una cilla. Asentado, se murió untestates

${ }^{39}$ Ib.: 419.

${ }^{40}$ Tres autores andinos proporcionan evidencias sobre la importancia de establecer equivalencias entre autoridades. Uno es Juan de Santa Cruz Pachacuti, que reproduce una canción, cantada por el seńor de Hatunqolla durante el matrimonio de Viracocha Inca, el octavo Inca de la geneaología oficial, en la que compara su estatus con el estatus de Viracocha (Santa Cruz Pachacuti 1993: 217). Otro es Titu Cusi, quien observa que el corregidor del Cuzco, el doctor Gregorio Cuenca, no ocupa el mismo plano que él, pues él se compara con el propio rey de España (Julien 2006: 83). La prueba de que esta preocupación es andina y no espańola viene de Guaman Poma, expuesta más abajo, que riñe amargamente sobre el hecho de que un criado del rey haya tenido la soberbia de matar al Inca.

${ }^{41}$ Guaman Poma 1992, II: 420-423. 
y despidió desta uida. Y acabó su uida sentiéndose el dolor de no uer la cara de su rey y señor». ${ }^{42}$ Toledo no murió intestado, ${ }^{43}$ pero esta referencia y la manera en que su muerte es representada-sentado en una silla y no en una cama- hace posible identificar este episodio en la crónica de Guaman Poma como un caso de la mala muerte.

Hay otra semejanza. Como Garcilaso, Guaman Poma identifica el pecado responsable del trágico fin del virrey: la soberbia. Esta es referida cuando Guaman Poma menciona la falta de jurisdicción de Toledo para juzgar al Inca. Y vuelve sobre este punto cuando describe su muerte:

De los males que había hecho en este rreyno, ací al Ynga como a los prencipales yndios y a los conquistadores deste rreyno, ues aquí, caualleros, la soberuia que tiene un mandado pobre. Se quiso alsarse como se alsó y mató a un rrey y señor deste rreyno. No pudiendo conoser la causa, cino el mismo rrey y señor a de sentenciar y firmar pa[ra] la sentencia y muerte de otro señor y rrey. Y ací la soberbia mató a don Francisco de Toledo. ${ }^{44}$

Garcilaso también menciona la soberbia del virrey, aunque su lectura de que el virrey tuvo una mala muerte fue porque pecaba sobre todo de avaricia.

Las semejanzas en la manera de estructurar sus narrativas, el uso del contraste entre la buena y la mala muerte, y el fuerte contenido moral parecen ser aspectos de una versión de esta historia que ambos autores usaban como fuente. Esta versión enfatiza el drama de la muerte del Inca que se realizó públicamente en el Cuzco. La escenificación es importante, y podemos verlo también en el encuentro entre Toledo y el rey que relata Garcilaso. Ambos autores tienen sus coincidencias, pero no son versiones independientes la una de la otra. Si acertamos bien en que beben de una fuente común, debemos de preguntar ¿cuál es el origen de esta historia? Guaman Poma estaba en el Perú y Garcilaso en España cuando Toledo ocupaba el cargo de virrey, y ninguno cruzó el mar en

\footnotetext{
42 Ib.: 424 .

43 Para el testamento de Toledo, fechado el 11 de marzo de 1580, véase Levillier 1935 1942, I: 90-181.

44 Guaman Poma 1992, II: 424.
} 
los siguientes años. Es probable que tuviera su origen en los Andes. La muerte del Inca fue un punto traumático en la historia de la conquista para las poblaciones andinas y es lógico que aparezca una manera de representarla que satisficiera al pueblo que sentía fuertemente este evento.

Hay otra confirmación de nuestra propuesta. Esta versión no es la única historia de la muerte del Inca; otra versión de la misma historia trata de la muerte de Atahualpa y no de Topa Amaru. ${ }^{45}$ Esta otra versión tiene una trayectoria muy larga en los Andes y sigue siendo representanda en la sierra andina hasta hoy. ${ }^{46}$ La existencia de más de una versión de la misma historia subraya la importancia del tema en la memoria andina. Garcilaso mantenía contacto con el Perú. Es perfectamente posible que él la haya escuchado de alguna visita que tuvo; no dejó de ser un autor andino por el simple hecho de establecerse en España.

\section{LA HISTORIA VS. LA MEMORIA}

Queda por definir un término para referirse a la memoria colectiva que se transmite de boca en boca. La mejor palabra en este caso sería memoria, aun cuando tiene otros sentidos, pues es importante dibujar una diferencia entre historia y memoria. En los siglos XVI y XVII, existía un género fácilmente reconocible como historia, con sus propias normas y pautas, aunque estas eran diferentes de aquellas que rigen a la historia moderna. La historia siempre trata de ser fehaciente a lo que pasó. Se fundamenta en evidencias. La existencia de estas y el acceso del historiador a las mismas son factores que convalidan lo que se escribe. $\mathrm{Al}$ mismo tiempo, hay otras versiones de la historia que circulan de boca a boca. Aparecen cuando un tema tiene un interés especial para una colectividad. No tienen autoría fija. Reflejan algo fehaciente, pero no buscan la verdad en la precisión sino en la resonancia de lo que se cuente

45 Se nota un interés creciente, a partir del siglo XVII, en la captura de Atahuallpa en Cajamarca y su ajusticiamiento por Pizarro. Por ejemplo, Giovanni Anello Oliva dedica mucho espacio al tema, en comparación con la poca mención que hace de los Incas de Vilcabamba (1998: 93, 125-139). La muerte de Atahuallpa también vino a ser tema en el arte visual (Gisbert 1980: 199-204).

46 Burga Díaz 1988. 
con los valores de las personas que lo repiten. Satisfacen una necesidad común de decir una verdad importante. El tema de la muerte del Inca cumple admirablemente con este propósito.

La separación de géneros no es siempre fácil y, como hemos visto, en el caso de los Comentarios reales, un autor puede beber de diversas fuentes. Cuando preguntamos si vale la pena hacer la separación, pienso que sí. Si no la hacemos, no podemos rescatar el género de la memoria que acabo de definir, pues se conserva en textos escritos. Aun cuando nuestra meta se limita a entender algo acerca de nuestro autor Garcilaso, nos importa. Cuando Garcilaso concluye su obra maestra con el tema de la muerte del Inca, nos muestra que, a pesar de los largos años que ha pasado en España, todavía comparte los valores de su pueblo de origen. La otra razón para separar la memoria de lo que podemos definir como historia sería para cumplir con nuestra función como historiador. Solamente así podríamos decir que Toledo sufrió una mala muerte, no aquella que nos cuentan Garcilaso y Guaman Poma, sino la propia suya.

\section{BIBLIOGRAFÍA}

Alcaya, Diego Felipe de. 1906. «Relación del padre Diego Felipe de Alcaya, cura de Mataca». En Maurtua, Víctor M. (ed.). Juicio de Limites entre el Perú y Bolivia. Prueba peruana presentada al gobierno de la república Argentina. Barcelona: Imprenta de Henrich y Comp., t. IX, 124-144.

Burga Díaz, Manuel. 1988. Nacimiento de una utopia: muerte y resurrección de los Incas. Lima: Instituto de Apoyo Agrario.

Fernández Navarrete, Miguel; Salvá, Miguel y Pedro Sáinz de Baranda (eds.). 1842-1895. Colección de documentos inéditos para la historia de España. Madrid: Ginesta Hermanos, Impresores de la real casa, 113 vols.

Garcilaso Inca de la Vega. Historia general del Perú. 1617. Córdoba: Viuda de Andrés Barrera.

. 1960. «Historia general del Perú. Segunda parte de los Comentarios reales». En Obras completas del Inca Garcilaso de la Vega. Edición de Carmelo Sáenz de Santa María. Madrid: Ediciones Atlas, t. IV.

Gisbert, Teresa. 1980. Iconografía y mitos indigenas en el arte. La Paz: Gisbert y Cía. Guaman Poma de Ayala, Felipe. 1992. El primer nueva corónica y buen gobierno. Edición de John V. Murra y Rolena Adorno. México, D. F.: Siglo Veintiuno, 3 vols. 
Guillén Guillén, Edmundo. 1977. «Documentos inéditos para la historia de los incas de Vilcabamba: La capitulación del gobierno español con Titu Cusi Yupanqui». Historia y Cultura. Núm. 10: 47-93.

Herrera y Tordesillas, Antionio de. 1601-1615. Historia general de los hechos de los castellanos en las islas i tierra firme del mar oceano. Madrid: Imprenta Real.

Julien, Catherine. 1999. «History and Art in Translation: The Paños and other Objects Collected by Francisco de Toledo». Colonial Latin American Review. Vol. 8, núm. 1: 61-69. . 2002. «Punchao en España». En Flores Espinoza, Javier y Rafael Varón Gabai (eds.). El hombre y los Andes. Homenaje a Franklin Pease G. Y. Lima: Pontificia Universidad Católica del Perú. https://doi.org/10.4000/books.ifea.6710 . 2006. «Titu Cusi Yupanqui amenaza declarar la guerra». En Zevallos-Aguilar, Juan; Takahiro Kato y Luis Millones (eds.). Ensayos de cultura virreinal latinoamericana. Lima: Universidad Nacional Mayor de San Marcos, 79-96. 2007. «Francisco de Toledo and his Campaign Against the Incas». Colonial Latin American Review. Vol. 16, núm. 2: 239-268.

Levillier, Roberto. 1921-1926. Gobernantes del Perú. Cartas y papeles, siglo XVI. Madrid: Imprenta de Juan Pueyo, 14 vols. . 1935-1942. Don Francisco de Toledo. Madrid, 4 vols. . 1956. «Don Felipe II y el virrey Toledo; un duelo de doce años». Revista de la Universidad de Buenos Aires. V época, año 1, núm. 2: 3-17.

López Martínez, Héctor. 1967. "Un motín de mestizos en el Perú, 1567». Revista de Indias. Vol. 24, núms. 97-98: 367-381.

Martínez Gil, Fernando. 1993. Muerte y sociedad en la España de los Austrias. México, D. F.: Siglo Veintiuno Editores.

Nowack, Kerstin. 2006. «Las mercedes que pedía para su salida: the Vilcabamba Inca and the Spanish state, 1539-1572». En Cahill, David y Blanca Tovías (eds.). New world, first nations: native peoples of Mesoamerica and the Andes under colonial rule. Brighton y Portland: Sussex Academic Press, 57-91.

Nowack, Kerstin y Catherine Julien. 1993. «La campaña de Toledo contra los señores naturales andinos: el destierro de los Incas de Vilcabamba y Cuzco». Historia y Cultura. Núm. 23: 15-81.

Ocampo, Baltasar de. 1906. «Descripción de la provincia de Vilcabamba». En Maurtua, Víctor M. (ed.). Juicio de Limites entre el Perú y Bolivia. Prueba peruana presentada al gobierno de la república Argentina. Barcelona: Imprenta de Henrich y Comp., t. VII, 308-344.

Oliva, Giovanni Anello. 1998. Historia del reino y provincias del Perú. Edición de Carlos M. Gálvez Peña. Lima: Pontificia Universidad Católica del Perú.

Pacheco, Joaquín; Cárdenas, Francisco y Luis Torres de Mendoza. 1864-1884. Colección de documentos inéditos relativos al descubrimiento, conquista y organización de las antiguas posesiones españoles de América y Oceania, sacados de los 
archivos del reino, y muy especialmente dél de Indias. Madrid: Imprenta de Frias y Compañía, 42 vols.

Santa Cruz Pachacuti Yamqui Salcamaygua, Juan de. 1993. Relación de antigüedades deste reyno del Pirú. Cuzco: Centro de Estudios Regionales Andinos Bartolomé de Las Casas.

Shäfer, Ernst. 1931. «Felipe II, el Consejo de Indias y el virrey D. Francisco de Toledo». Investigación y Progreso. Año V, núms. 7-8: 103-107.

Titu Cusi Yupanqui, Diego de Castro. 1985. Ynstruçión del ynga Don Diego de Castro Titu Cussi Yupangui para el muy ilustre Señor el licenciado Lope García de Castro, governador que fue destos reynos del Piru. Lima: El Virrey. 